\title{
Evolutionary transformations of the malleus in pinnipeds, with emphasis on Southern Hemisphere taxa
}

\author{
Cleopatra M. Loza ${ }^{1,2}$, Oliver Reutimann ${ }^{3}$, Marcelo R. Sánchez-Villagra ${ }^{3}$, Alfredo A. Carlini ${ }^{1,2}$, Gabriel Aguirre- \\ Fernández ${ }^{3,4}$ \\ ${ }^{1}$ Laboratorio de Morfología Evolutiva y Desarrollo (MORPHOS), and División Paleontología de Vertebrados, \\ Museo de La Plata, Facultad de Ciencias Naturales y Museo, Universidad Nacional de La Plata, Paseo del \\ Bosque s/n, B1900FWA La Plata, Argentina \\ ${ }^{2}$ CONICET, Consejo Nacional de Investigaciones Científicas y Técnicas, Argentina \\ ${ }^{3}$ Paläontologisches Institut und Museum (PIMUZ),Universität Zürich, Karl-Schmid Strasse 4, CH-8006, Zürich, \\ Switzerland \\ ${ }^{4}$ E-mail: gabriel.aguirre@pim.uzh.ch
}

Keywords: adaptation, aquatic mammals, middle ear, ossicles, phylogeny

\begin{abstract}
The systematic value of the middle-ear ossicles, in particular the malleus, has been long recognized for diverse groups. We present systematic work on the characters of the middle-ear ossicles of pinnipeds, focusing on until now poorly studied Southern Hemisphere species. Mallei were extracted from 16 specimens of pinnipeds belonging to five austral and one boreal species of Phocidae and two austral species of Otariidae. Several characters used in this study have been described previously, and some were here modified. Three new characters are here defined and analysed. All characters were mapped onto the phylogeny. Our character analysis shows the transformations that have occurred in the evolution of middle ear ossicles in pinnipeds and identifies diagnostic features of many of its clades. Beyond the identification of specific changes within eachclade, our study of pinniped ossicle evolution documents the occurrence of anatomical convergences with other groups of mammals that live in an aquatic environment, as has occurred in other organ systems as well.
\end{abstract}

\section{Contents}

Introduction ..... .75

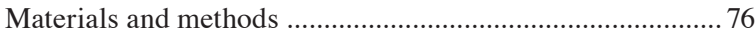

Results and discussion ............................................................ 76 Anatomical description of the otariid and phocid malleus .76

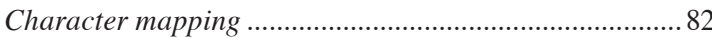

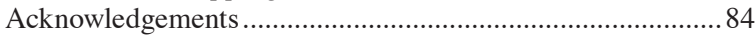

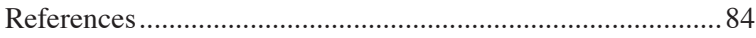

Appendix .85

\section{Introduction}

The systematic value of the middle-ear ossicles, in particular the malleus, has been long recognized for diverse groups (Schmelzle et al., 2005; Wible and Spaulding, 2012) ever since the outstanding descriptions by Hyrtl (1845) and Doran (1878) and their accurate drawings. The comparative anatomy of the ossicles of carnivorans has been particularly well studied (Wible and Spaulding, 2012), and among these studies those on pinnipeds are noteworthy given the aquatic specializations and high disparity of this group (Figure 1; Fleischer, 1973). We here present a systematic work on the characters of the middle-ear ossicles of pinnipeds, in part expanding on previous works (e.g., Berta and Wyss, 1994; Wyss, 1987) and particularly focusing on until now poorly studied Southern Hemisphere species. Doran (1878) described and figured the ossicles of a variety of pinnipeds. A brief description and drawings of the ear ossicles of Ommatophoca rossii were included in the anatomical description by King (1969), and a description and photos of those of the austral species were included in Loza (2016). The middle-ear ossicles of the extinct stem pinnipedimorph Pteronarctos were described and figured in Berta (1994), whereas those of the extinct odobenid Imagotaria downsi were described and figured in Repenning and Tedford (1977). 


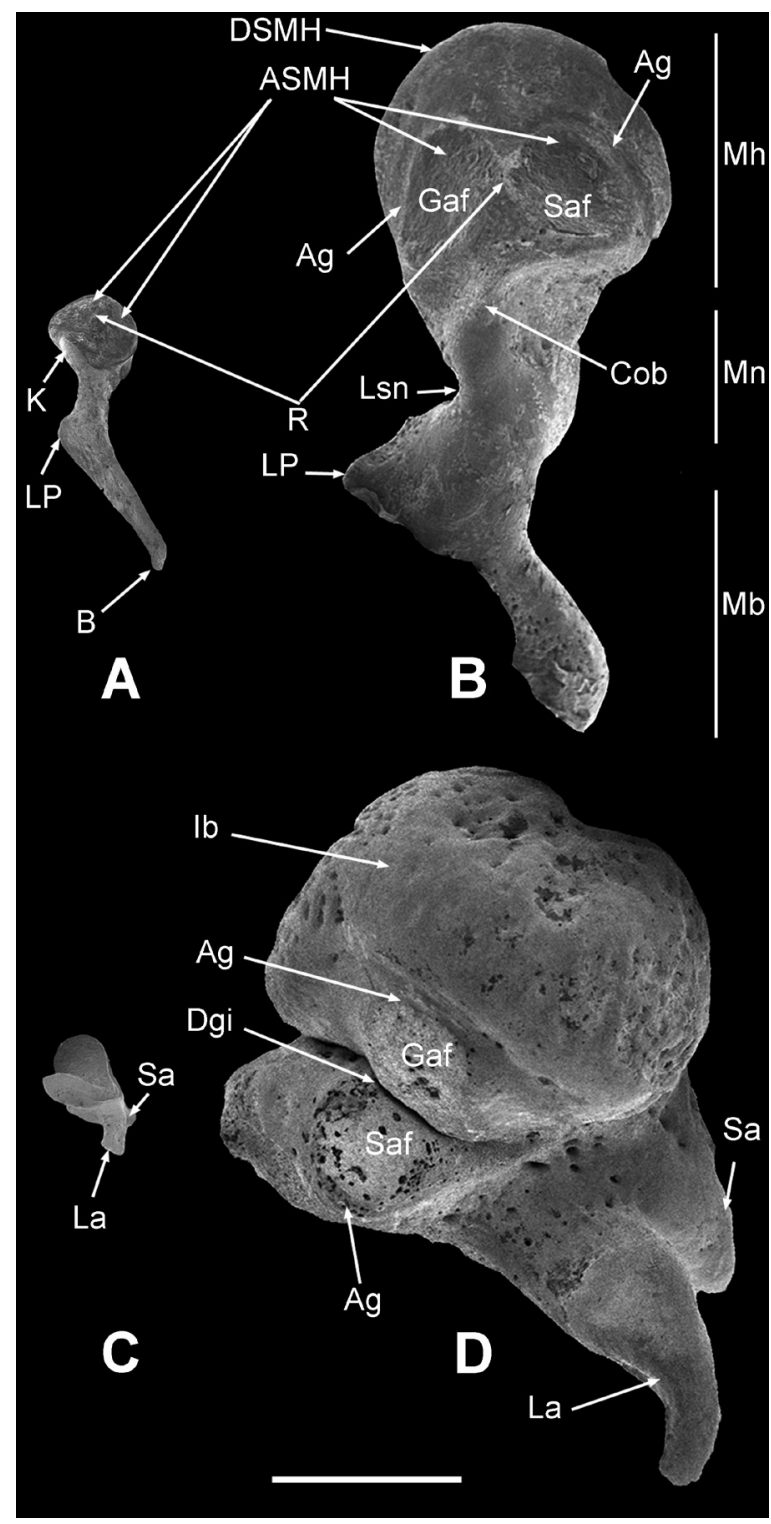

Figure 1. Ossicles of Otariidae (left) and Phocidae (right). Amalleus of Arctocephalus gazella, B- malleus of Mirounga leonina, C- incus of Arctocephalus gazella, and D- incus of Mirounga leonina. Abbreviations: (Ag) Anchor groove; (ASMH) Articulation surface on the malleolar head; (B) "Beck"; (Cob) Crista obliqua; (Dgi) Deep groove of the incus; (DSMH) Dorsal surface of the malleolar head; (Gaf) Greater articular facet; (Ib) Incus body; (K) keel; (La) Long arm; (Lp) Lateral process; (Lsn) Lateral sulcus of the neck; (Mb) Manubrium; (Mh) Malleolar head; (Mn) Malleus neck; (Sa) Small arm. Scale bar $=5 \mathrm{~mm}$.

\section{Materials and methods}

Mallei were extracted from 15 specimens of austral pinnipeds (belonging to five species of Phocidae and two species of Otariidae), one specimen of a northern phocid (Phoca vitulina), and one ursid (Ursus maritimus) (Table 1). Images were obtained with a scanning electron microscope (SEM) Jeol JSM 6360LV at the Electronic Microscopy Center of the Museo de La Plata, except for the malleus of Phoca vitulina which was scanned at the Center for Microscopy and Image Analysis of the University of Zurich using a JEOL JSM-6010, a tungsten cathode scanning electron microscope. The specimens were not coated and the SEMs were set to low voltage. Middleear ossicles of Ursus maritimus were photographed using a camera (Leica DFC $420 \mathrm{C}$ ) mounted on a stereoscopic microscope Leica MZ 16. Other taxa were included based on Doran's (1878) drawings (Table 1). Two fossil species were added to the analysis based on published descriptions and illustrations: the stem pinnipedimorph Pteronarctos goedertae from Berta (1994) and the odobenid Imagotaria downsi from Repenning and Tedford (1977).

We used the standardized nomenclature of middleear ossicles of Wible and Spaulding (2012). Several characters used in this study were introduced by Wyss (1987), and Berta and Wyss (1994); some were modified here (Table 2). Three new characters are here defined and analysed. All characters were mapped onto a phylogeny using Mesquite V.3.31 (Maddison and Maddison, 2017). The topology used to map the characters is mostly based on Arnason et al. (2006); fossil pinnipeds were added according to Boessenecker and Churchill (2015). The mallei were measured (malleus length, manubrium length, manubrium percentage of the total length of the malleus, head length, and head percentage of the total length of the malleus) using a binocular microscope (Figure 2 and Online Supplementary Information 1). We followed the taxonomy as given in Wilson and Mittermeier (2014).

\section{Results and discussion}

\section{Anatomical description of the otariid and phocid malleus}

The pinniped malleus has two very different morphologies, and the characters that we discuss here are shown in Figure 3. The otariid malleus (Figure 1A) 
Table 1. Specimens of pinnipeds studied. AC: Cátedra de Anatomía Comparada, Facultad de Ciencias Naturales y Museo, Universidad Nacional de La Plata, La Plata, Buenos Aires, Argentina; IAA: Instituto Antártico Argentino, Departamento Biología Predadores Tope (Buenos Aires, Argentina); MACN: Museo de Ciencias Naturales Bernardino Rivadavia (Buenos Aires, Argentina); MLP: Museo de La Plata (La Plata, Argentina); ZMZ: Zoological Museum of the University of Zurich (Zurich, Switzerland).

\begin{tabular}{|c|c|c|c|}
\hline Family & Taxon & Specimen & Age and sex \\
\hline Mustelidae & Martes martes & Doran (1878: plate LIX fig. 7) & \\
\hline Procyonidae & Procyon lotor & Doran (1878: plate LIX fig. 11) & \\
\hline \multirow[t]{2}{*}{ Ursidae } & Ursus maritimus & Doran (1878: plate LVIII fig. 36) & \\
\hline & Ursus maritimus & ZMZ 15199 & juvenile \\
\hline Stem pinniped & Pteronarctos goedertae $\dagger$ & Berta (1994) & \\
\hline \multirow{23}{*}{ Phocidae } & Pagophilus groenlandicus & Doran (1878: plate LIX fig. 30) & \\
\hline & Pusa hispida & Doran (1878: plate LIX fig. 31) & \\
\hline & Phoca vitulina & Doran (1878: plate LIX fig. 27) & \\
\hline & Phoca vitulina & Doran (1878: plate LIX fig. 28) & \\
\hline & Phoca vitulina & ZMZ 13125 & \\
\hline & Cystophora cristata & Doran (1878: plate LIX fig. 25) & \\
\hline & Erignathus barbatus & Doran (1878: plate LIX fig. 29) & \\
\hline & Hydrurga leptonyx & AC-2014/1 & adult \\
\hline & Leptonychotes weddellii & MACN 49253 & adult \\
\hline & Leptonychotes weddellii & IAA-02.15 & adult \\
\hline & Leptonychotes weddellii & IAA-01.13 & adult \\
\hline & Leptonychotes weddellii & MLP 31.XII.02.23 & adult \\
\hline & Lobodon carcinophaga & AC764-c & adult \\
\hline & Lobodon carcinophaga & IAA-542 & adult female \\
\hline & Lobodon carcinophaga & IAA-541 & adult \\
\hline & Lobodon carcinophaga & AC-2002/4 & adult \\
\hline & Lobodon carcinophaga & Doran (1878: plate LIX fig. 26) & \\
\hline & Ommatophoca rossii & MACN 48.260 & juvenile female \\
\hline & Mirounga leonina & IAA-00-9 & adult female \\
\hline & Mirounga leonina & AC-2002/3 & adult male \\
\hline & Mirounga leonina & AC-2002/6 & adult male \\
\hline & Mirounga leonina & Doran (1878: plate LIX fig. 23) & \\
\hline & Mirounga leonina & Doran (1878: plate LIX fig. 24) & \\
\hline \multirow[t]{4}{*}{ Odobenidae } & Imagotaria downsi† & Repenning and Tedford (1977) & \\
\hline & Odobenus rosmarus & Doran (1878: plate LIX fig. 21) & \\
\hline & Odobenus rosmarus & Doran (1878: plate LIX fig. 22) & \\
\hline & Odobenus rosmarus & Kasteleinet al. (1996) & juvenile male \\
\hline \multirow[t]{5}{*}{ Otariidae } & Arctocephalus gazella & AC- $2014 / 3$ & adult male \\
\hline & Eumetopias jubatus & Doran (1878: plate LIX fig. 20) & \\
\hline & Otaria byronia & AC-2014/2 & adult male \\
\hline & Otaria byronia & Doran (1878: plate LIX fig. 18) & \\
\hline & Otaria byronia & Doran (1878: plate LIX fig. 19) & \\
\hline
\end{tabular}


Table 2. Ear ossicles of pinnipeds: character description

1. Muscular process on malleus: $0=$ present; $1=$ reduced; 2 = absent (Modified, Wyss, 1987: character 21; Berta and Wyss, 1994: character 47).

2. Anterior concavity on malleolar head: $0=$ absent; $1=$ present (Wyss, 1987: character 24).

3. Osseous lamina and rostral process on malleus: $0=$ unreduced; 1 = rudimentary or absent (Wyss, 1987: character 23; Berta and Wyss, 1994: character 48).

4. Relative length of manubrium in respect to the total length of malleus: $0=>55 \% ; 1=55 \%$ or smaller (modified, Wyss, 1987: character 26).

5. Relative size of malleolar head: $0=$ standard $(20 \%)$; $1=$ enlarged $(20-40 \%) ; 2=>40 \%$ (new character).

6. Malleus: $0=$ standard; $1=$ enlarged (Wyss, 1987 : character 22; Berta and Wyss, 1994: character 46).

7. Articulation surface on malleolar head: $0=$ semicircular facets; 1 = circular facets (modified, Wyss, 1987: character 25).

8. Extra articular surface: $0=$ absent; $1=$ present (new character, based on text from Hyrtl, 1845).

9. Dorsal part of head in posterior view; $0=$ smooth rounded surface; 1 = articular surface extends to the dorsal part of the head; 2 = osseous bulge (new character, based on text from Doran, 1878).

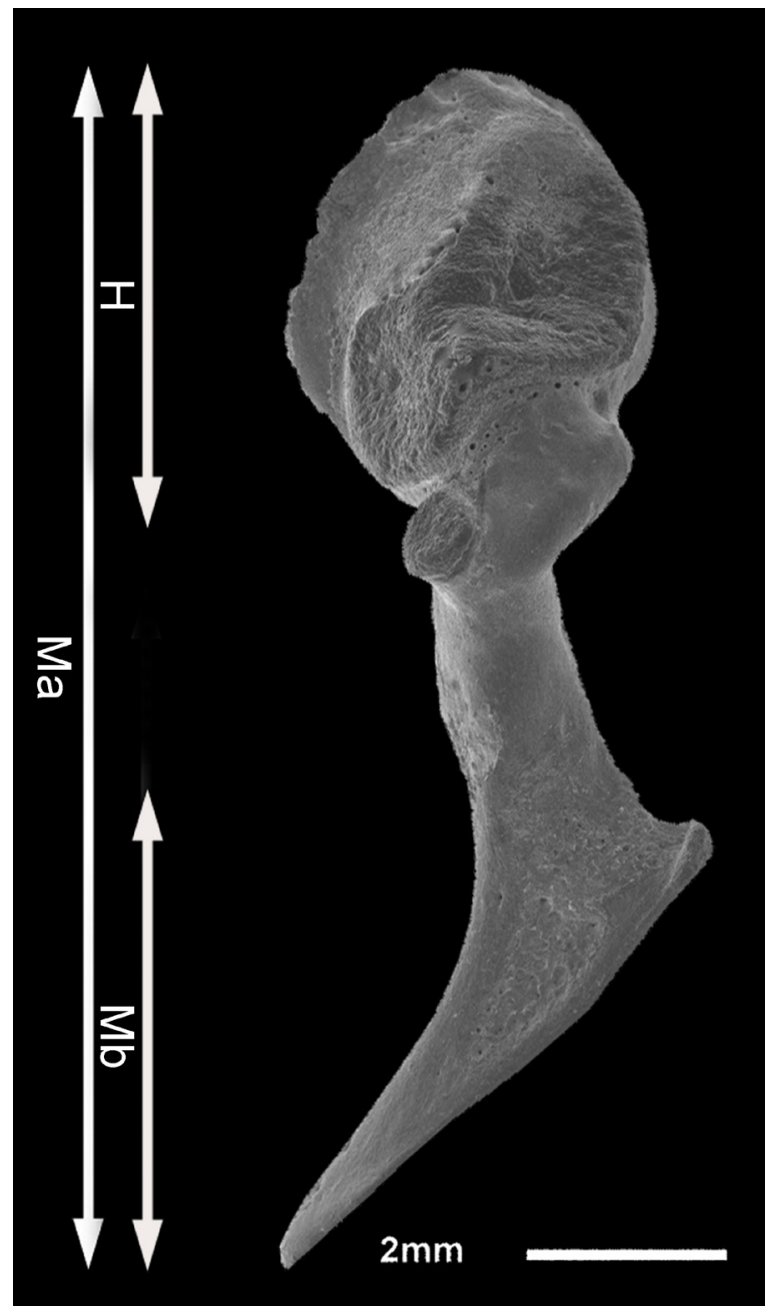

Figure 2: Malleus of Phoca vitulina. Measurements used: H, head length; Ma, malleus length; Mb, manubrium length.

whereas the muscular process is not visible.

The head of the malleus of phocids is proportionally much larger than that of otariids. It is anteroposteriorly compressed and sub-triangular to sub-circular in shape. The anterior surface is irregular with some striations and is traversed on its lateral border by a deep groove (ASMH), which forms the osseous lamina (Ol) (Figure 5B-D, I)(towards the beginning of the neck, ending in a rostral process (RP), which is large compared with that of otariids).

Posteriorly (Figures 1,4), the articulation zone consists of two joint facets, one superior (Saf) and one inferior (Iaf), both with variable contour according to the species and separated by a convex ridge (R) (Doran, 1879). Dorsally on the head of the malleus of phocids, 
there is a laminar extension of bone (DSMH). Each articular facet is surrounded by an anchoring groove $(\mathrm{Ag})$. A crest runs obliquely (oblique crest, $\mathrm{Cob}$ ) from the most lateral part of the head to its center. Unlike in otariids, the neck of phocids is short. There is a "lateral groove of the neck" (Lsn) between the head of the malleus and the lateral process.

The phocid manubrium ( $\mathrm{Mb})$ is long and has a triangular section in its first half (moderately evident in L. weddellii); distally it flattens and becomes thinner. It has a triangular and spatulate lateral process (LP), which is shorter in L. weddellii and $O$. rossii than in other phocids.

The rostral process (RP) is well developed, short and projects from the head.

The muscular process (MP) is not evident in $M$. leonina and in P. vitulina (where it is merelya rough area for insertion), but is present in all other examined phocids.

The malleus of $L$. weddellii, $L$. carcinophaga, $H$. leptonyx and $O$. rossii is relatively smaller than that of M. leonina. Among phocids, mallei show different shapes and arrangements of the articular facets; those of $L$. weddellii are larger than those of M. leonina relative to the size of the head, they are sub-oval in outline, the medial being the largest. Those of L. carcinophaga are similar in size relative to those of $L$. weddellii, but with a sub-quadrangular outline; those of the latter two species and those of $H$. leptonyx are arranged as one medial and one lateral facet. The facets of $O$. rossii are rotated ( $\sim 90$ degrees) in respect to their position in other phocids and are convex.

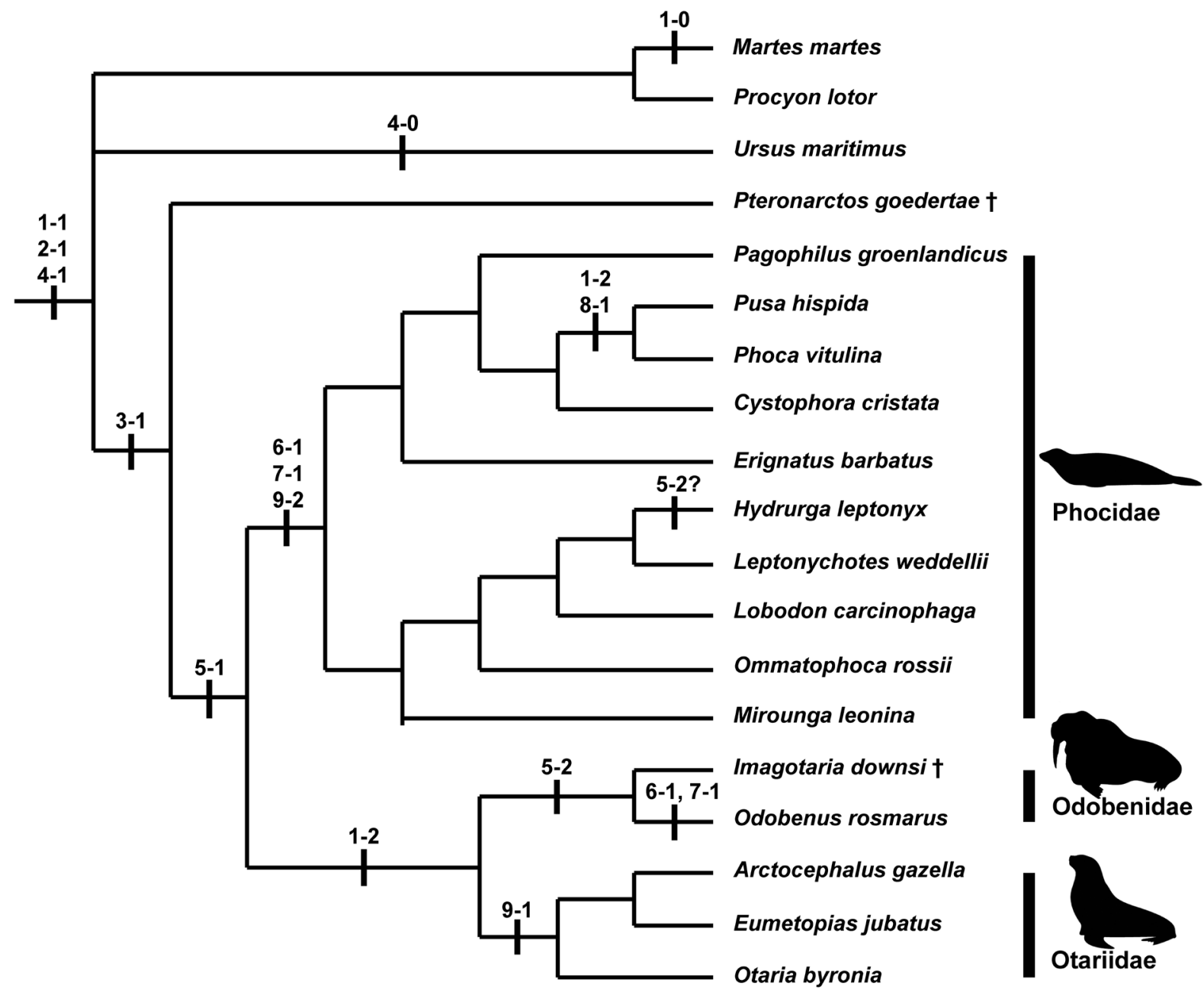

Figure 3. Composite tree from Arnason et al. (2006) and, Boessenecker and Churchill (2017), displaying the mapping of malleus characters (left number, character; right number, state). 


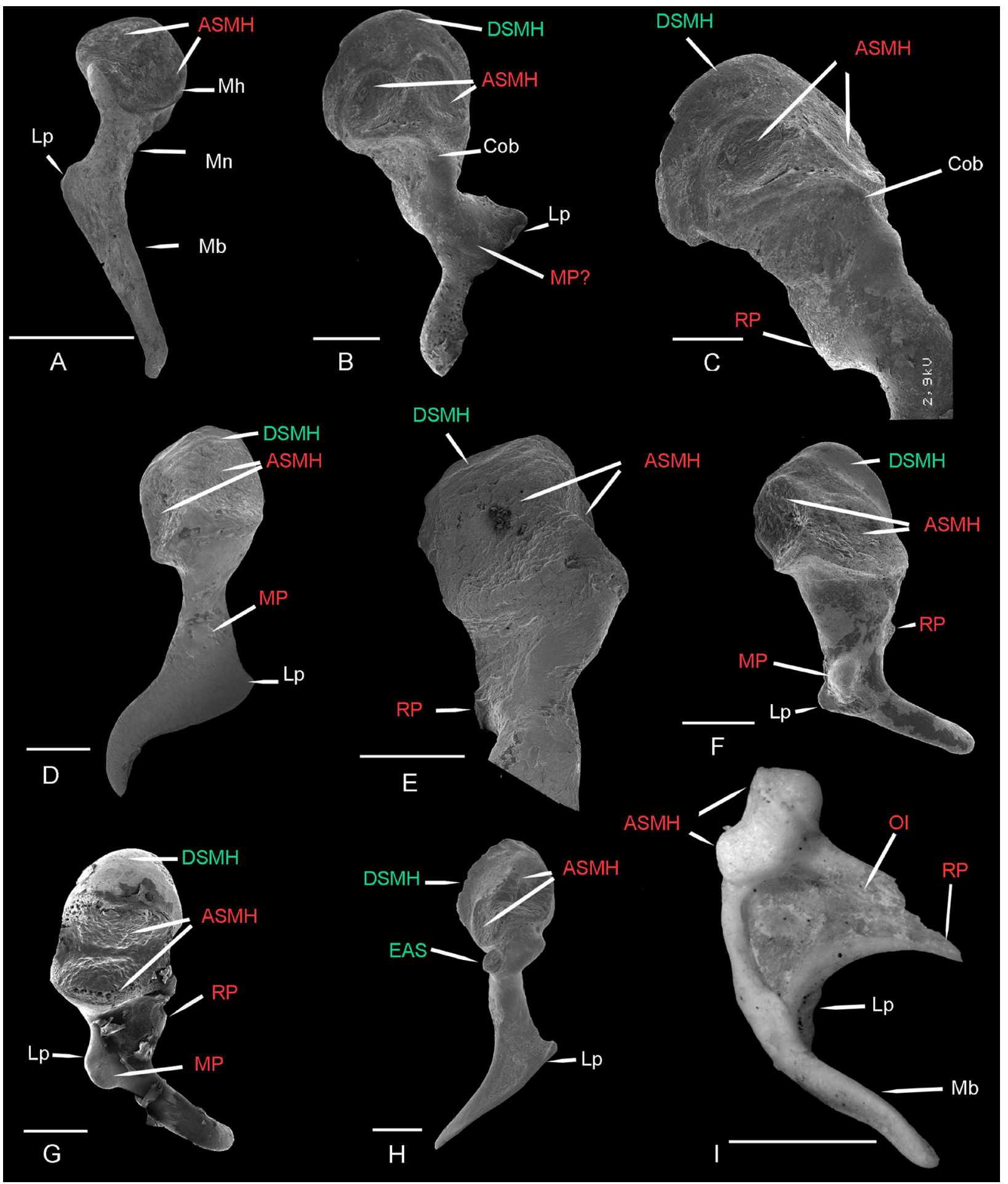

Figure 4. Compared mallei, showing the analyzed characters. A- Arctocephalus gazella (right, in posterior view), B- Mirounga leonina (left, in posterior view), C- Mirounga leonina (left, detail in postero-medial view), D- Lobodon carcinophaga (left, in posterior view), E- Lobodon carcinophaga (left, detail in postero-medial view), F- Leptonychotes weddellii (right, in posterior view), G- Ommatophoca rossii (right, in posterior view), H- Phoca vitulina (left, in posterior view), I- Ursus maritimus (right, medial view). Abbreviations: (ASMH) Articulation surface on the malleolar head; (Cob) Crista obliqua; (DSMH) Dorsal surface of the malleolar head; (EAS) extra articulating surface; (Lp) Lateral process; (Mb) Manubrium; (Mh) Malleolar head; (Mn) Malleus neck; (MP) Muscular process; (Ol) Osseous lamina; (RP) Rostral process. In green new characters, in red characters previously used by other authors, in white other structures. Scale bar= $2 \mathrm{~mm}$. 


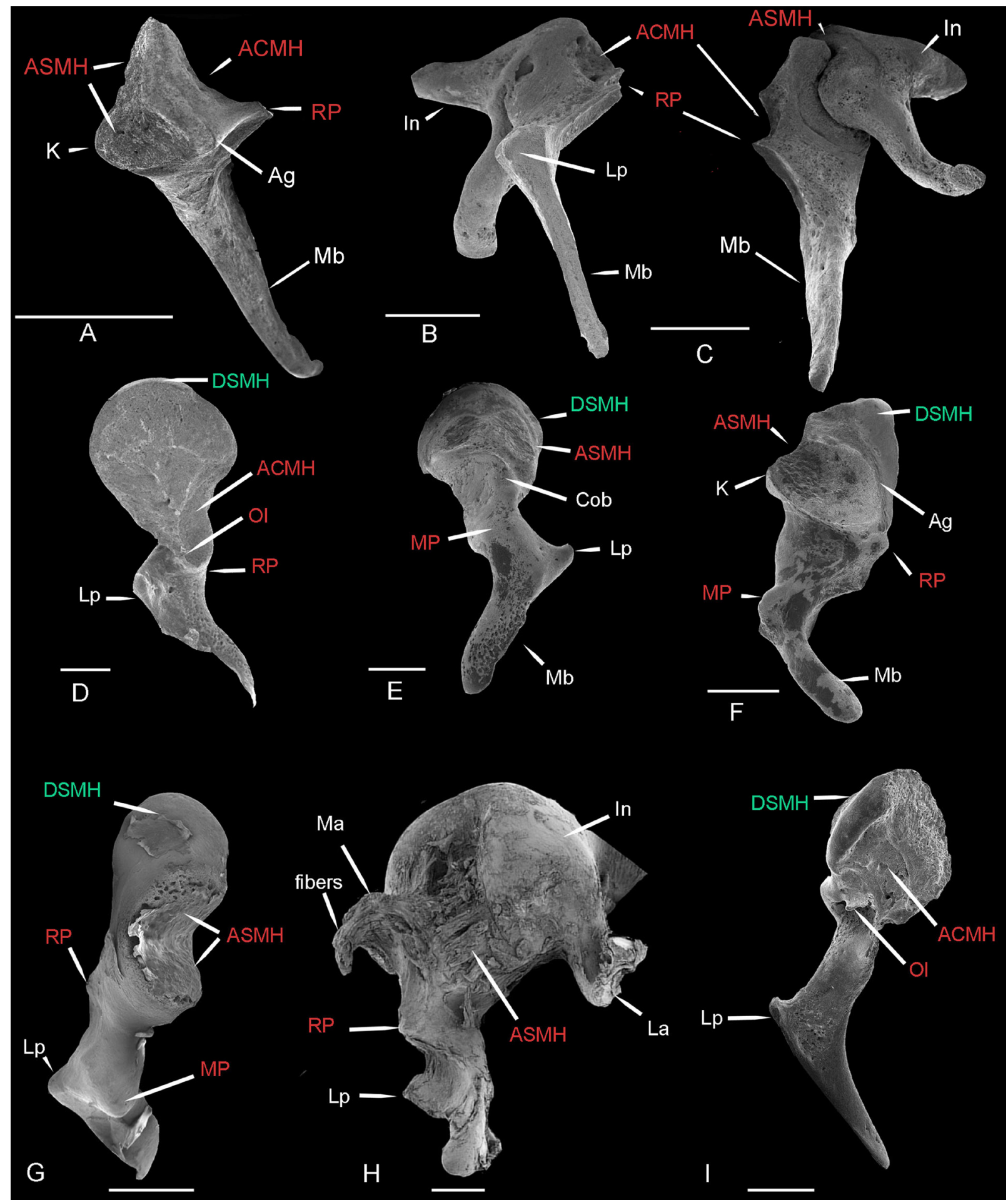

Figure 5. Compared mallei, showing the analyzed characters. A- Arctocephalus gazella (right, in dorsal view), B- Otaria byronia (malleus and incus in anterior view), C- Otaria byronia (articulated left malleus and incus in medial view), D- Mirounga leonina (left, in anterior view), E- Mirounga leonina (left, in postero-ventral view), F- Leptonychotes weddellii (right, in medial view), G- Ommatophoca rossii (right, in lateral view), H- Hydrurga leptonyx (articulated left malleus and incus in medial view), I- Phoca vitulina (left, in anterior view). Abbreviations: (ACMH) Anterior concavity of Malleolar head; (Ag) Anchor groove; (ASMH) Articulation surface on the malleolar head; (Cob) Crista obliqua; (DSMH) Dorsal surface of the malleolar head; (In) Incus; (K) keel; (La) Long arm; (Lp) Lateral process; (Ma) Malleus; (Mb) Manubrium; (MP) Muscular process; (Ol) Osseous lamina; (RP) Rostral process. In green, new characters; in red, characters previously used by other authors; in white, other structures. Scale bar $=2 \mathrm{~mm}$. 
With respect to the incus, in addition to the obvious differences in size between those of otariids and phocids, in the latter the incus has a globular body so that the joint surfaces are proportionally small relative to the rest of the body, while in otariids the joint surface is greater. A deep groove (Dgi) is observed on the articular facets of the incus of phocids, which is not present in otariids.

\section{Character mapping}

Our character analysis shows the transformations that have occurred in the evolution of the malleus in pinnipeds and identifies diagnostic features of its clades. In a terrestrial environment (where sound travels in the air), the middle ear increases the pressure of created by the sound to surpass the impedance of the fluid around the organ of Corti. Variations in size and shape of the middle ear ossicles relate to hearing acuteness. In an aquatic environment the middle ear is practically useless because the sound may enter any part of the head and be transmitted directly to the organ of Corti (Reppening, 1972; Hemilä et al., 2006). The changes of the middle ear ossicles in pinnipeds are therefore affected by different degrees of aquatic occupation, whereby size changes have played a major role (Repenning 1972). Cetaceans and sirenians differ from pinnipeds in the retention of a muscular process on the malleus and the lack of an anterior concavity on the head of the malleus; their mallei are also several times more massive than those of phocids (Wyss, 1987).

Doran (1878) already noted the extreme reduction of the muscular process of the malleus (MP) (Figure 3: character 1; Table 2; Figures 4,5) in ursids and some musteloids, for example procyonids. This character was discussed in Berta and Wyss (1994), who reported that based on the sample at the Field Museum of Natural History "the muscular process is indeed invariably absent in bears". Our examination of a juvenile specimen of Ursus maritimus (ZMZ 15199) contradicts this observation: the muscular process is reduced, but visibly present. The muscular process (Figure 3: character 1; Figure 4) in pinnipeds is even more reduced or completely absent. Rudimentary muscular processes were observed in Ursus maritimus (not visible in the medial view of Figure 4I), Pteronarctos, and some phocids (Phoca groenlandicus, Erignathus barbatus, Leptonychotes weddellii, Ommatophoca rossii, Lobodon carcinophaga; see Figure 4B, D, F, G; Figure $5 \mathrm{D}, \mathrm{F})$, whereas the mallei of otariids bear no trace of a muscular process. Doran (1878) observed the absence of the muscular process in Odobenus, but its presence is mentioned and illustrated in Kastelein et al. (1996). This ambiguity is represented in our scorings and considered a polymorphy. To conclude, the reduction of the muscular process is a symplesiomorphy for Pinnipedimorpha as this feature is shared with Ursidae and some musteloid families (e.g., procyonids). The complete absence of a muscular process characterizes otariids and possibly odobenids (Figure 5A-C), whereas in phocids this feature is variable, being much reduced in some species (Figure $5 \mathrm{E}-\mathrm{G}$ ). The threshold between an extremely reduced muscular process and its absence is difficult to establish.

An anterior concavity on the malleolar head (ACMH) (Figure 3: character 2; Table 2; Figure 5AD, I) was reported by Doran (1878) for all pinnipeds, including Odobenus. The same condition is also known for ursids (Wyss, 1987), including Ursus maritimus. The presence of this concavity in adult specimens of Odobenus was contested by Wyss (1987), although he did find it in young individuals and hence scored it as present in his analysis. The photographs of Odobenus in Kastelein et al. (1996: fig. 19) show this concavity, but the specimen is indeed a young (two years old) individual. As the concavity is clearly present in the fossil odobenid Imagotaria downsi, the absence of it in adult specimens of Odobenus, if confirmed, would be an autapomorphy for the species.

The rostral process (RP) and osseous lamina of the malleus (Ol) (Figure 3: character 3; Table 2; Figures 4, 5) are well-developed in Ursus maritimus, whereas in the stem pinnipedimorph Pteronarctos they are smaller. These two structures are also reduced in all examined pinnipeds, but the degree of reduction is difficult to quantify (see Figure 5D, I -an Ol for Phoca vitulina-). Fleischer (1973) opened the skulls to study the ossicles in their natural position. He reported a rather long rostral process for Phoca vitulina (Fleischer, 1973. fig. 55) and Arctocephalus pusillus (Fleischer, 1973. fig. 54). In both cases the rostral process was fused to the tympanic part of the temporal bone. Wible and Spaulding (2012) pointed out that the osseous lamina in some mallei illustrated by Doran (1878) must be broken because of this fact. However, the drawings from Fleischer (1973) indicate at least a reduction of the osseous lamina and rostral process in pinnipeds compared to those in Ursus maritimus.

Based on Wyss (1987), we compared the proportion of the manubrium relative to the length of the malleus (Mb/Ma) (Figure 3: character 4; Table 2; Figure 2). The manubrium of Ursus maritimus $(60 \%$ of the malleus length) is the longest in our sample, but the 
relative manubrium length of Martes and Procyon falls within the range of pinnipeds. Therefore, the character is uninformative for the selection of taxa of interest.

The relative enlargement of the head of the malleus (Figure 3: character 5; Figures 3,4) is a synapomorphy of Pinnipedia. While the relative size of the head of the malleus is enlarged in phocids and otariids (Figure 3: character 5-1), this enlargement is most extreme in odobenids (Figure 3: character 5-2).

In comparison with other carnivorans of similar size, the middle-ear ossicles of phocids have often been considered as greatly enlarged (e.g., Doran, 1878; Repenning, 1972; Wyss, 1987). Nummela (1995: Table 1 and Fig. 2) compared the collective weight of malleus and incus with that of the skull among mammals and found that the ossicles of phocids are remarkably massive in respect to their skulls, whereas in many other mammals (including the otariid Callorhinus ursinus) the skull and ossicle weights are strongly correlated. Strong intraspecific variation in body size (and weight), sometimes related to age and sexual dimorphism (which is most extreme in Mirounga leonina; Hammill, 2008), limits the ability to generalize and use this character more objectively. For a proper assessment, one should analyze the skull and its associated middle ear ossicles for a few specimens of each species, including males and females and possibly specimens from different geographic areas. The remarkable enlargement of the middle ear ossicles in phocids, cetaceans and sirenians clearly indicates adaptations to an aquatic life. The detailed mechanism for pinniped hearing underwater remains unclear and it is possible that sound causes the whole head to vibrate. In such a scenario, the massive ossicles may be advantageous for underwater hearing by providing a differential motion between the stapes and the vibrating cochlear capsule (Hemilä et al., 2006 and references therein).

The shape of each articular facet (inferior and superior) on the malleolar head (character 7; Table 2; Figure 3) is circular in phocids and Odobenus, whereas it appears semicircular in otariids (Figure 4). Furthermore, the articular facets of otariids are enlarged in proportion compared to the other pinnipeds. In carnivorans, the articular facets are generally broad, but in phocids and odobenids the articular facets are smaller, perhaps the shape is linked to the increased size of the head (Wyss, 1987). An exceptional arrangement of the articular facets was observed in $O$. rossii, where the two facets are in convergence instead of divergence to each other (Figures 4G; 5G), and ca.
$90^{0}$ rotated with respect to the position of the malleus in the other pinnipeds studied here.

Character 8 was first described by Hyrtl (1845), but has never been scored in an analysis.It refers to a small, thick process below the articulation surface near the base of the neck of the malleus (= "dicker Fortsatz" in Hyrtl, 1845:65). This secondary articulation is directed to a similar structure on the incus (Fleischer, 1973; Hyrtl, 1845)(our EAS in Figure 4H). Doran (1878) referred to this structure as an "extra articulating surface" (our EAS) and it is illustrated for Phoca vitulina (Doran, 1878: Plate LIX, fig. 28) and Pusa hispida (Doran, 1878: Plate LIX, fig. 31). According to Doran (1878), this may be a modified muscular process. We found it in ZMZ specimen of Phoca vitulina (see Figure 4F) and also scored it in Pusa hispida based on the observations of Hyrtl (1845).

The shape of the malleolar head dorsal to the articulation surface (Figure 3, character 9; Table 2; Figures 4,5$)$ is diagnostic at the family level. The area above the articulation surface in Ursus, Martes, Procyon and odobenids is a smooth rounded surface of small extent, representing the globular part of the head, as seen in other mammals (e.g. Felis, Canis, Lontra, Nassua, Suricata; see Doran, 1878). Phocids show a prominent and rather concave osseous bulge, whereas in otariids there is no visible bone dorsal to the articulation surface (Figure 4B-H vs. Figure 4A, I).

Beyond the identification of specific changes within each clade, our study of pinniped ossicle evolution documents the occurrence of anatomical convergences with other groups of mammals related to the aquatic environment, as has occurred in other organ systems (e.g. modified limbs, reduction of the external earsize, achievement of a thick periferal fat layer). Examples discussed here are the enlargement of the malleus, the shortening and thickening of the manubrium, andthe enlargement of the incus (see Online Supplementary material 2 -compared incus-).

In the inner ear, Loza et al. (2017) reported how the Ross seal (Ommatophoca rossii), the most aquatic of pinnipeds, has reduced semicircular canals and proportionally reduced para flocculus relative to those of other phocids, in parallel with what is known for cetaceans. Our study discovered unique features of the Ross seal in the malleus that suggest a transformation similar to that of cetaceans expressed in the convergence of the articular facets of the malleus to each other(e.g. Doran, 1878: Plate LXII) instead of divergence. These facets are ca. $90^{0}$ rotated as compared to other pinnipeds. Functional studies 
(Hemilä et al. 1995; Mason, 2016) might reveal the potential mechanical significance of this change (see discussion in Solntseva, 2013), should it have any.

\section{Acknowledgements}

We thank Martina Schenkel (University of Zurich) Drs. I. Olivares, D. Verzi and L. Soibelzon (Museo de La Plata), S. Lucero and D. Flores (Museo Argentino de Ciencias Naturales "B. Rivadavia"), and J. Negrete (Instituto Antártico Argentino) for access to specimens; Patricia Sarmiento and Jorge Carrillo Briceño are thanked for scanning specimens using SEM. Robert Boessenecker (College of Charleston) is thanked for useful discussions. We specially thank Dr. Nummela and Dr. Costeur for their suggestions, that improved this manuscript. This work was partially funded by Universidad Nacional de La Plata N-724.

\section{References}

Arnason U, Gullberg A, Janke A, Kullberg M, Lehman N, Petrov EA, Väinölä. 2006. Pinniped phylogeny and a new hypothesis for their origin and dispersal. Molecular Phylogenetics and Evolution 41:345-354. https://doi. org/10.1016/j.ympev.2006.05.022.

Berta A. 1994. New specimens of the pinnipediform Pteronarctos from the Miocene of Oregon. Smithsonian Contributions to Paleobiology 78: 1-30.

Berta A, Wyss A. 1994. Pinniped phylogeny. Pp. 33-56 in: A. Berta and TA Deméré, eds, Contributions in Marine Mammal Paleontology Honoring Frank C. Whitmore, Jr.Proceedings of the San Diego Society of Natural History 29. California, USA.

Boessenecker RW, Churchill M. 2015. The oldest known fur seal. Biology Letters 11: 20140835.doi: 10.1098/rsbl.2014.0835.

Doran AHG. 1878. XVIII. Morphology of the Mammalian Ossicula auditûs. Transactions of the Linnean Society of London, 2nd Series: Zoology 1:371-497. 10.1111/j.10963642.1878.tb00663.x.

Fleischer G. 1973. Studien am Skelett des Gehörorgans der Säugetiere, einschließlich des Menschen. Säugetierkundliche Mitteilungen 21:131-239.

Hammill, MO. 2008. Earless seals. Pp. 342-348 in WF Perrin, B Würsig, JGM Thewissen, eds, Encyclopedia of Marine Mammals. Amsterdam: Elsevier.

Hemilä S, Nummela S, Reuter T. 1995. What middle ear parameters tell about impedance matching and high frequency hearing. Hearing research 85:31-44.

Hemilä S, Nummela S, Berta A, Reuter T. 2006. High-frequency hearing in phocid and otariid pinnipeds: An interpretation based on inertial and cochlear constraints. Journal of the Acoustic Society of America 120: 3463-3466.

Hyrtl J. 1845. Vergleichend-anatomische Untersuchungenüber das innere Gehörorgan des Menschen und der Säugethiere. Prag: F. Ehrlich.

Kastelein R, Dubbeldam J, De Bakker M, Gerrits N. 1996. The anatomy of the walrus head (Odobenus rosmarus). Part 4 :
The ears and their function in aerial and underwater hearing. Aquatic Mammals 22: 95-126.

King JE. 1969. Some aspects of the anatomy of the Ross seal, Ommatophoca rossii (Pinnipedia: Phocidae). British Antarctic Survey Scientific Reports 63. British Antarctic Survey. Cambridge, UK.

Loza CM. 2016. Nomenclatura osteológica y accidentes de la región ótica de pinnípedos y sinónimos. Revista del Museo de La Plata 1:117-158.

Loza CM, Latimer A, Sánchez-Villagra M, Carlini AA. 2017. Sensory anatomy of the most aquatic of carnivorans: the Antarctic Ross seal, and convergences with other mammals. Biology Letters13 (10):20170489 doi.org/10.1098/ rsbl.2017.0489.

Maddison MP, Maddison DR. 2017. Mesquite: a modular system for evolutionary analysis. Version 3.40. http:// mesquiteproject.org.

Mason MJ. 2016. Structure and function of the mammalian middle ear. II: Inferring function from structure. Journal of anatomy 228: 300-312.

Repenning, C. 1972. Underwater hearing in seals. Pp. $307-$ 331 in: R. Harrison, ed., Functional Anatomy of marine mammals, Volume I. London: Academic Press.

Repenning CA, Tedford RH. 1977. Otarioid seals of the Neogene: classification, historical zoogeography, and temporal correlation of the sea lions and walruses from the North Pacific region. US Government Printing Office.

Schmelzle T, Nummela S, Sánchez-Villagra MR. 2005. Phylogenetic transformations of the ear ossicles in marsupial mammals, with special reference to diprotodontians: a character analysis. Annals of Carnegie Museum 74: 189-200.

Solntseva G. 2013. Adaptive features of the middle ear of mammal in ontogeny. Acta Zoologica Bulgarica, 65, 101116.

Wible JR, Spaulding M.2012. A Reexamination of the Carnivora Malleus (Mammalia,Placentalia). PLoS ONE 7:e50485. 10.1371/journal.pone.0050485.

Wilson DE, Mittermeier RA (editors) 2014. Handbook of the Mammals of the World. Vol. 4. Sea Mammals. Barcelona: Lynx Edicions.

Wyss AR. 1987. The walrus auditory region and the monophyly of pinnipeds. American Museum Novitates, 2871:1-31.

Received: 5 February 2018

Revised and accepted: 30 April 2018

Published online: 18 July 2018

Editor: A. van der Geer

\section{Online supplementary information}

S1. Specimen of pinnipeds studied and measurements of the malleus

S2. Compared incus of southern pinnipeds 


\section{Appendix}

Matrix Character / Taxon used in the analysis; for character description see Table 2

\begin{tabular}{|c|c|c|c|c|c|c|c|c|c|}
\hline Taxon / Character & 1 & 2 & 3 & 4 & 5 & 6 & 7 & 8 & 9 \\
\hline Martes martes & 0 & $?$ & 0 & 1 & 0 & 0 & 0 & 0 & ? \\
\hline Procyon lotor & 1 & $?$ & 0 & 1 & 0 & 0 & 0 & 0 & ? \\
\hline Ursus maritimus & 1 & 1 & 0 & 0 & 0 & 0 & 0 & 0 & 0 \\
\hline Pteronarctos goedertae & 1 & 1 & 1 & 1 & 0 & 0 & $?$ & $?$ & 0 \\
\hline Pagophilus groenlandicus & 1 & $?$ & 2 & 1 & 1 & 1 & 1 & 0 & 2 \\
\hline Pusa ispida & 2 & 1 & 2 & 1 & 1 & 1 & 1 & 1 & 2 \\
\hline Phoca vitulina & 2 & 1 & 2 & 1 & 1 & 1 & 1 & 1 & 2 \\
\hline Cystophora cristata & 2 & 1 & 2 & 1 & 1 & 1 & 1 & 0 & 2 \\
\hline Erignatus barbatus & 1 & $?$ & 2 & 1 & 1 & 1 & 1 & 0 & 2 \\
\hline Hydrurga leptonyx & 1 & 1 & 2 & 1 & 2 & 1 & $?$ & 0 & 2 \\
\hline Leptonychotes weddellii & 1 & 1 & 2 & 1 & 1 & 1 & 1 & 0 & 2 \\
\hline Lobodon carcinophaga & 1 & 1 & 2 & 1 & 1 & 1 & 1 & 0 & 2 \\
\hline Ommatophoca rossii & 1 & 1 & 2 & 1 & 1 & 1 & 1 & 0 & 2 \\
\hline Mirounga leonina & 1 & 1 & 2 & 1 & 1 & 1 & 1 & 0 & 2 \\
\hline Imagotaria downsi & $?$ & 1 & 1 & 1 & 2 & $?$ & $?$ & $?$ & 0 \\
\hline Odobenus rosmarus & $1 \& 2$ & 1 & 1 & 1 & 2 & 1 & 1 & 0 & 0 \\
\hline Arctocephalus gazella & 2 & 1 & 1 & 1 & 1 & 0 & 0 & 0 & 1 \\
\hline Eumetopias jubatus & 2 & $?$ & $?$ & 1 & 1 & 0 & 0 & 0 & 1 \\
\hline Otaria byronia & 2 & 1 & 1 & 1 & 1 & 0 & 0 & 0 & 1 \\
\hline
\end{tabular}

